\title{
DIARREIA NEONATAL POR ROTAVÍRUS EM BEZERROS DA RAÇA ABERDEEN ANGUS-RELATO DE CASO
}

Recebido: $12 / 05 / 2015$

\author{
PIZONI, Camila ${ }^{1}$; \\ SCHERER, Bárbara ${ }^{2}$; \\ RIVERO, Beatriz Riet Corrêa ${ }^{1}$; \\ RAIMONDO, Raquel Fraga e Silva ${ }^{1}$; \\ KUNZ, Andressa Fernanda ${ }^{3}$; \\ TAKIUCHI, Elisabete ${ }^{4}$; \\ CORRÊA, Marcio Nunes ${ }^{1}$; \\ RABASSA, Viviane Rohrig ${ }^{1}$.
}

Aceito: $21 / 11 / 2015$

${ }^{1}$ NUPEEC-Núcleo de Pesquisa, Ensino e Extensão em Pecuária, Faculdade de Veterinária, Universidade Federal de Pelotas; ${ }^{2}$ Médica Veterinária, autônoma; ${ }^{3}$ Médica Veterinária, Bolsista, Fundação Araucária; ${ }^{4}$ Professora, Doutora, Curso de Medicina Veterinária, Universidade Federal do Paraná-Campus Palotina.

\section{RESUMO}

- ste relato descreve casos de rotavirose em bezerros, filhos de vacas vacinadas contra a - enfermidade, durante a gestação, oriundos de uma propriedade localizada no Sul do Rio Grande do Sul. Os animais eram da raça Aberdeen Angus, com uma semana de idade, mantidos em sistema extensivo. Na visita à propriedade foi realizado exame clínico em 19 animais e, por amostragem, realizada coleta de sangue e fezes. Os bezerros que apresentaram diarreia foram tratados com antimicrobianos, repositor eletrolítico, imunoestimulante e probiótico. No leucograma foi possível observar leucocitose por linfocitose e no exame de fezes pela técnica de eletroforese em gel de poliacrilamina (SDSPAGE) foi possível identificar a presença do genoma viral do Rotavirus em três animais. No exame bacteriológico de fezes foi identificada a presença de Escherichia coli, caracterizando infecção multifatorial em alguns animais. Concluiu-se que bezerros de mães vacinadas para rotavirose podem desenvolver a doença, possivelmente devido a falhas no protocolo vacinal e/ou na ingestão de colostro, comprometendo a transferência da imunidade passiva colostral.

Palavras-chave: Neonatos. Vírus. Bovinos de corte. 


\section{INTRODUÇÃO}

A diarreia em bezerros é uma enfermidade cosmopolita que afeta os neonatos nas primeiras semanas de vida. É uma das principais responsáveis por perdas econômicas por apresentar altos índices de morbidade e mortalidade (WEI et al., 2013), além de reduzir o ganho de peso e aumentar os custos da produção (VEGA et al., 2011). Em bovinos neonatos é uma doença de etiologia multifatorial que resulta da interação do animal com o ambiente, a nutrição e os agentes infecciosos (BENESI, 1999).

São três os mecanismos de absorção e secreção na mucosa intestinal que podem sofrer alterações devido à etiologia da doença. O primeiro é relacionado com a diarreia nutricional, sendo chamado de hipersecreção passiva e tem relação com fatores hemodinâmicos, inflamatórios ou substâncias osmótico-ativas, por exemplo, a lactose mal digerida. $\mathrm{O}$ segundo mecanismo é relacionado às diarreias bacterianas e tem como mecanismo a hipersecreção ativa, causada principalmente por Escherichia coli e Salmonella spp. O último mecanismo se refere à redução da absorção e reabsorção de água e eletrólitos, normalmente causada por coronavírus e rotavírus (BOUDA et al., 2000).

O rotavírus bovino é um dos agentes mais comumente envolvido na diarreia neonatal (ALFIERI et al., 2004). Como estratégia de controle, preconiza-se a vacinação das mães aos 60 e 30 dias pré-parto, para que haja transferência de imunidade passiva através da ingestão do colostro (VEGA et al., 2011).

Como a placenta das vacas é do tipo sinepiteliocorial, não há passagem de imunoglobulinas por essa via (LESLIE et al., 2007), tornando os bezerros dependentes da ingestão do colostro para adquirir imunidade contra agentes infecciosos, os melhores resultados ocorrem se a ingestão se dá em até seis horas após o parto (VASSEUR et al., 2010). Três fatores podem limitar a transferência de imunidade passiva para os bezerros: colostro em quantidade e/ou qualidade insuficiente, ingestão de quantidade inadequada de colostro e falhas na absorção intestinal de imunoglobulinas pelos bezerros (SANTOS, 2001). Esses fatores podem contribuir para que a transferência da imunidade, através do colostro de mães vacinadas no pré-parto, muitas vezes seja ineficaz. 
O objetivo deste estudo foi relatar casos de rotavirose em bezerros de corte, mantidos em sistema extensivo de produção, destacando os fatores epidemiológicos envolvidos, o diagnóstico e tratamento utilizados.

\section{RELATO DE CASO}

Em novembro de 2013, uma propriedade de recria de bovinos de corte da raça Aberdeen Angus com aproximadamente 540 animais, localizada no município de Cristal (RS), solicitou atendimento ao Núcleo de Pesquisa, Ensino e Extensão em Pecuária (NUPEEC), da Faculdade de Veterinária da Universidade Federal de Pelotas (UFPEL).

A propriedade contava com uma área de 640 ha, sendo 90 ha de azevém e o restante de campo nativo. $\mathrm{O}$ azevém era manejado pelo proprietário entre as categorias do rebanho, priorizando os bezerros recém desmamados. Devido ao manejo nutricional realizado na propriedade, as vacas, mães dos bezerros avaliados, apresentavam-se magras em avaliação do escore de condição corporal realizado de acordo com Santos et al (2010).

As vacas eram vacinadas duas vezes ao ano (junho e dezembro) contra Rinotraqueíte Infecciosa Bovina (IBR), Diarreia Viral Bovina (BVD), Parainfluenza Tipo 3 (PI3), Vírus Sincicial Respiratório Bovino (BRSV), Leptospirose (sorovares Canicola, Grippotyphosa, Hardjo, Ictero haemorrhagiae e Pomona) e contra Clostridioses.

Em novembro de 2012 teve início a vacinação contra a Diarreia Neonatal de Bezerros. A vacina era destinada as vacas e novilhas prenhes, como um auxiliar na prevenção da diarreia dos bezerros causada por rotavírus (sorotipos G6 e G10), coronavírus, cepas enterotoxigênicas de $E$. coli com fator de aderência pili K99 e Clostridium perfringens tipo C. A vacina também era realizada duas vezes ao ano, juntamente com as outras vacinas. A época de parição dos animais iniciava em novembro e se estendia até fevereiro.

A queixa principal do proprietário era que os animais recém-nascidos apresentavam diarreia. De acordo com a anamnese, o quadro clínico era observado na primeira semana após o nascimento, sendo que os bezerros apresentavam melhora após tratamento com antibiótico de longa ação e após 30 dias voltavam a manifestar a enfermidade. A morbidade era de $100 \%$, porém sem mortalidade, ocasionando atraso no desenvolvimento dos animais. 
Durante a visita, foi realizado exame clínico dos bezerros recém-nascidos que ainda não haviam sido tratados, totalizando 19 animais. Foram avaliados os seguintes parâmetros: frequência cardíaca, frequência respiratória, tempo de preenchimento capilar, coloração de mucosas, temperatura retal e a consistência das fezes. As fezes foram classificadas, conforme Walker et al. (1998), em normais (bem formadas e firmes), anormais (levemente pastosas, mas sem caracterizar diarreia), pastosas (diarreia moderada) e líquidas (diarreia profusa).

De modo aleatório, foi coletado sangue de oito bezerros com diarreia, obtidos através de punção da veia jugular, e armazenados em tubos contendo EDTA (BD Vacutainer ${ }^{\circledR}$ ), para realização de hematócrito, proteínas plasmáticas totais (PPT) e leucograma.

As amostras de fezes dos bezerros foram colhidas diretamente da ampola retal. Dezesseis amostras foram enviadas para cultivo bacteriano em ágar sangue ovino, de acordo com as recomendações de Quinn et al. (1994); dez amostras foram enviadas para exame coproparasitológico para realização da contagem de ovos por grama de fezes (OPG), segundo a técnica de Gordon e Whitlock (1939); e dezesseis amostras para a deteç̧ão do genoma viral, pela técnica de eletroforese em gel de poliacrilamida conforme descrito por Pereira et al. (1983).

Após a colheita de material para exames laboratoriais, os bezerros com sintomatologia clínica foram tratados com sulfadoxina associada com o trimetoprim (Borgal ${ }^{\circledR}$, MSD Saúde Animal, Brasil), $15 \mathrm{mg} / \mathrm{Kg}$, IM, em dose única. Como tratamento de suporte foi utilizado o butafosfan associado com a cianocobalamina (Catosal B12 ${ }^{\circledR}$, Bayer Saúde Animal, Brasil) 10 $\mathrm{mL}$ /animal, IM, em dose única; probiótico (Floramax ${ }^{\circledR}$, Indústria de Medicamentos Veterinários S. A., Brasil), 5 g/animal/dia, VO, três dias; e repositor eletrolítico (Glutelac ${ }^{\circledR}$, Bayer Saúde Animal, Brasil), diluído em água, VO, uma vez ao dia, três dias. O tratamento instituído objetivou a redução dos sinais clínicos e a minimização das perdas econômicas decorrentes da enfermidade.

\section{RESULTADOS E DISCUSSÃO}

O exame clínico realizado durante a visita demonstrou que os parâmetros físicos dos animais avaliados estavam acima dos parâmetros fisiológicos para a espécie, segundo Dirksen et al. 
(1993), possivelmente em decorrência do manejo de contenção e manipulação dos animais para realização das coletas. Os animais apresentaram frequência cardíaca média de $108,3 \pm 32,6$ bpm, frequência respiratória média de $65,1 \pm 15,2 \mathrm{mpm}$, temperatura retal média $39,9 \pm 0,36^{\circ} \mathrm{C}$ e mucosas normocoradas.

Na avaliação das fezes, 63,2\% (12/19) dos bezerros apresentaram alterações na consistência, destes, 8,3\% (1/12) apresentaram fezes muco-sanguinolentas, 58,4\% (7/12) fezes pastosas e 33,3\% (4/12) fezes líquidas. Apenas 16,7\% (2/12) dos animais com alterações na consistência das fezes apresentaram sinais de desidratação (turgor cutâneo >3 segundos e enoftalmia). Quanto aos parâmetros sanguíneos, a Tabela 1 demonstra os valores do hematócrito, PPT (proteínas plasmáticas totais) e leucograma dos animais examinados durante a visita.

Tabela 1 - Avaliação dos parâmetros sanguíneos de oito bezerros da raça Aberdeen Angus com diarreia, de uma propriedade em Cristal/RS.

\begin{tabular}{ccccccc}
\hline Animal & $\begin{array}{c}\text { Leucócitos } \\
\text { Totais }(/ \boldsymbol{\mu L})\end{array}$ & Neutrófilos $(\boldsymbol{\mu L})$ & Linfócitos $(\boldsymbol{\mu L})$ & Monócitos $(\boldsymbol{\mu L})$ & Hematócrito \% & PPT $(\mathbf{g} / \mathbf{d L})$ \\
\hline $\mathbf{1}$ & 8600 & 3612 & 4386 & 602 & 30 & 8,2 \\
$\mathbf{2}$ & $13100^{*}$ & 1834 & $9694^{*}$ & $1048^{*}$ & 35 & 6,8 \\
$\mathbf{3}$ & $19900^{*}$ & $6567^{*}$ & $12736^{*}$ & 597 & 35 & 7,6 \\
$\mathbf{4}$ & $16900^{*}$ & 2366 & $13858^{*}$ & 676 & 35 & 7,0 \\
$\mathbf{5}$ & $14800^{*}$ & $4736^{*}$ & $9028^{*}$ & $1036^{*}$ & 38 & 6,6 \\
$\mathbf{6}$ & 11300 & 2260 & $8588^{*}$ & 339 & 33 & 7,6 \\
$\mathbf{7}$ & $15700^{*}$ & 3454 & $10205^{*}$ & $1099^{*}$ & 29 & 7,4 \\
$\mathbf{8}$ & $15100^{*}$ & $6191^{*}$ & $7701^{*}$ & 755 & 30 & 8,2 \\
\hline
\end{tabular}

*Animais que apresentaram alterações hematológicas segundo Jain (1991).

No leucograma foi possível observar que alguns animais apresentaram leucocitose por neutrofilia (JAIN, 1993), podendo caracterizar uma infecção aguda, tanto bacteriana como viral. Outros apresentaram leucocitose por linfocitose que, em bezerros neonatos, pode ser considerada fisiológica, ou ainda caracterizar doença de cunho viral, já que o vírus desencadeia uma maior reação antigênica e com isso uma maior resposta imunológica (THRALL et al., 2007).

Apesar dos valores do hematócrito e da PPT estarem compatíveis com os valores de referência (JAIN, 1993), é importante lembrar que alguns dos bezerros avaliados apresentaram sinais de desidratação. Na desidratação os valores de hematócrito e PPT se 
elevam, pois o sangue fica mais concentrado (THRALL et al., 2007), porém isso não foi observado nos animais avaliados, provavelmente devido à desidratação ser leve, sem causar grande variação nos parâmetros hematológicos.

No exame bacteriológico das fezes houve isolamento de agentes pertencentes a flora considerada normal para a espécie, com presença de Bacillus spp. e E. coli não hemolítica. Entretanto, das fezes de um bezerro houve o isolamento de $E$. coli hemolítica (Tabela 2), que é uma cepa patogênica e uma das principais causadoras de diarreia em neonatos (COURA et al., 2014). Os resultados do exame coproparasitológico foram negativos em todos os animais.

Tabela 2 - Resultados da pesquisa de bactérias e vírus nas amostras de fezes de bezerros da raça Aberdeen Angus com diarreia, de uma propriedade em Cristal/RS.

\begin{tabular}{lll}
\hline Animal & Isolamento Bacteriano & Identificação Viral \\
\hline $\mathbf{1}$ & E. coli não hemolítica & Negativo \\
$\mathbf{2}$ & Sem crescimento & - \\
$\mathbf{3}$ & E. coli não hemolítica & Negativo \\
$\mathbf{4}$ & Flora normal & - \\
$\mathbf{5}$ & Bacillus spp. & Negativo \\
$\mathbf{6}$ & E. coli não hemolítica & Negativo \\
$\mathbf{7}$ & Flora normal & Negativo \\
$\mathbf{8}$ & E. coli hemolítica & Positivo para rotavírus \\
$\mathbf{9}$ & Flora normal & Negativo \\
$\mathbf{1 0}$ & Sem crescimento & Positivo para rotavírus \\
$\mathbf{1 1}$ & E. coli não hemolítica & - \\
$\mathbf{1 2}$ & E. coli não hemolítica & Negativo \\
$\mathbf{1 3}$ & Sem crescimento & Positivo para rotavírus \\
$\mathbf{1 4}$ & Sem crescimento & - \\
$\mathbf{1 5}$ & Sem crescimento & Negativo \\
$\mathbf{1 6}$ & Bacillus spp. & Negativo \\
\hline
\end{tabular}

Na pesquisa do genoma viral foi detectado rotavírus em três amostras (Tabela 2). Os danos causados pelo rotavírus predispõem os animais a desenvolverem infecções secundárias, possivelmente devido à baixa imunidade em que se encontram (WHITLOCK, 1992; RAMIG, 2004). A partir dos resultados obtidos no exame bacteriológico das fezes e pela detecção do genoma viral por eletroforese em gel de poliacrilamida é possível afirmar que os casos clínicos de diarreia atendidos na propriedade em questão foram oriundos de infecção multifatorial, com destaque para o rotavírus bovino. 
Filho et al. (2007) demonstraram em um estudo realizado com bezerros da raça Nelore, criados extensivamente, acometidos por diarreia, detecção de micro-organismos em 79\% das amostras de fezes. Nesse grupo, em $51,9 \%$ das amostras foi identificado somente um agente e em $48,1 \%$ das amostras foram identificados múltiplos agentes, constatando um alto grau de sinergismo entre os agentes da diarreia em bezerros, como observado no presente estudo.

O rotavírus é um vírus encontrado no ambiente e comumente se faz presente no intestino dos animais adultos. As manifestações clínicas da doença estão relacionadas a diversos fatores como nível de imunidade contra o vírus, sorotipo, infecção concomitante, estresse, lotação, entre outros (RAMIG, 2004).

Na propriedade em questão, a vacinação era realizada duas vezes ao ano sem levar em conta a época de parição. No caso da vacinação contra a Diarreia Neonatal de Bezerros, a recomendação do fabricante é que esta seja realizada 60 e 30 dias pré-parto. Por esse motivo, possivelmente, a quantidade de imunoglobulinas transferida, através do colostro, para os bezerros estivesse diminuída, dificultando o combate de infecções no pós-parto. Além disso, a vacina utilizada era específica para os sorotipos $\mathrm{G} 6$ e G10, não contendo na sua formulação o sorogrupo A, que segundo Saif e Jiang (1994) é o mais importante na ocorrência de diarreia por rotavírus em humanos e bovinos. Em um estudo realizado por Buzinaro et al. (2003) foi encontrada uma prevalência de rotavírus tipo A de 41,7 a $82,4 \%$ nas fezes de bezerros de corte com diarreia. Ainda, o sorogrupo A possui uma alta variabilidade e complexidade dentro do mesmo grupo e isso dificulta a eficácia das medidas de profilaxia e controle da doença (ASANO et al., 2011).

O tratamento utilizado no presente caso teve como objetivo reposição eletrolítica, controle de infecções secundárias, reposição da microbiota bacteriana e estimulo da imunidade. Foi iniciado antes do diagnóstico de rotavirose ser confirmado laboratorialmente, na intenção de reduzir as perdas econômicas conforme recomendado por Benesi (1999).

Como estratégia para o controle da doença, recomenda-se melhorar o escore de condição corporal das vacas durante a gestação, programar a parição para épocas com maior disponibilidade de pastagem (GULLIKSEN et al., 2008) e vacinar as fêmeas no terço final da 
gestação, para que a transferência de imunidade passiva ocorra da melhor forma possível (CASTRUCCl et al., 1988). Em humanos, a transferência de imunidade passiva da mãe para o feto e para o recém-nascido é realizada através da transferência placentária e pela ingestão do colostro, fazendo com que haja um imediato e temporário estado de imunidade. Contudo, nos ruminantes, como relatado anteriormente, o tipo de placenta não permite a transferência de imunidade que fica dependente da ingestão do colostro (CHUCRI et al., 2010). A absorção das imunoglobulinas, especialmente da classe $G$ (IgG) presentes no colostro da mãe, garantirão a proteção no período inicial de vida dos bezerros (TIZARD, 2002).

No presente relato, suspeita-se que houve falha na passagem de anticorpos das mães para os bezerros. As causas podem ser: colostragem inadequada (quantidade e/ou qualidade insuficiente), baixa condição corporal das vacas, ou ainda em decorrência do protocolo vacinal utilizado.

Foi recomendado ao proprietário ajustar o calendário de vacinação das fêmeas de acordo com o período de parição, melhorar a condição corporal das vacas com estratégias nutricionais e garantir a correta ingestão de colostro levando-se em consideração qualidade e quantidade ingeridas.

\section{CONCLUSÃO}

O presente relato demonstrou que bezerros filhos de mães vacinadas para rotavirose podem desenvolver a doença quando o protocolo vacinal não for seguido corretamente e/ou quando houver falha na ingestão de colostro.

\section{NEONATAL DIARRHEA CAUSED BY ROTAVIRUS IN ABERDEEN ANGUS CALVES- CASE REPORT}

\section{ABSTRACT}

T his report aims to describe the rotavirus occurrence in calves born from cows previously vaccinated against the disease during pregnancy originated from a south Brazilian property. The animals were Aberdeen Angus, with one week of age, reared in extensive system. Clinical examination was performed in 19 calves, blood and faeces 
collection was also performed. Animals with diarrhea were treated with antibiotics, electrolyte replacer, immune-stimulant and probiotic. The leukocyte count indicated leukocytosis with lymphocytosis and fecal samples, analyzed by electrophoresis with polyacrylamide gel (SDS-PAGE), detected the viral genome confirming the presence of rotavirus in 3 animals. The fecal bacteriological examination indicated the presence of Escherichia coli, characterizing a multifactorial infection in some of the calves. In conclusion, calves born from cows vaccinated against Rotavirus can develop the disease, possibly due to failures in the vaccination protocol and/or in case of a failure during colostrum intake, which may compromise the colostral passive immunity transfer.

Keywords: Neonates. Virus. Beef cattle.

\section{DIARREA NEONATAL POR ROTAVÍRUS EN TERNEROS DE RAZA ABERDEEN ANGUS-RELATO DE CASO}

\section{RESUMEN}

E ste relato tiene como objetivo describir un brote de rotavírus en terneros hijos de vacas vacunadas para rotavírus en la gestación, que eran de un predio ganadero en el sul del Rio Grande do Sul. Los animales eran de la raza Aberdeen Angus, con una semana de edad y mantenidos en sistema extensivo. En la propiedad fue realizado examen clínico de 19 animales y por muestreo fue realizada colección de sangre y heces. Los animales con diarrea fueron tratados con antibióticos, restaurador de electrolitos, inmunoestimulante y probiótico. En el recuento de leucocitos fue observada leucocitosis por linfocitosis y en el examen de heces por la técnica de electroforesis en gel de poliacrilamina (SDS-PAGE) fue posible la detección del genoma viral de rotavírus en tres animales. En el examen bacteriológico de las heces se encontró la presencia de Escherichia coli, caracterizando la infección multifactorial en algunos animales. Se concluyó que los terneros de vacas vacunadas contra la enfermedad por Rotavirus pueden desarrollar la enfermedad, posiblemente debido a fallas en los protocolos vacúnales y/o cuando hay fallas en la ingestión de calostro comprometiendo la transferencia de inmunidad pasiva calostral.

Palabras clave: Neonatos. Virus. Ganado de carne. 


\section{REFERÊNCIAS}

ALFIERI, A. F.; ALFIERI A. A.; BARREIROS, M. A. B.; et al. G and P genotypes of group A rotavírus strains circulating in calves in Brazil, 1996-1999. Veterinary Microbiology, v. 99, n. 3-4, p. 167-173, 2004.

ASANO, K. M.; GREGORI, F.; SOUZA, S. P.; et al. Bovine rotavírus in turkeys with enteritis. Avian Diseases, v. 55, n. 4, p. 697-700, 2011.

BENESI, F. J. Síndrome diarreia dos bezerros. Revista CRMV-ES, v. 2, p. 10-13, 1999.

BOUDA, J.; MEDINA, M.; QUIROZ-ROCHA, G. Diarreia no Bezerro: etiopatogenia, tratamento e prevenção. In: GONZÁLES, F. H. D.; BORGES, J. B.; CECIM, M. (Eds.). Uso de provas de Campo e de laboratório clínico em doenças metabólicas e ruminais dos bovinos. Porto Alegre: Editora UFRGS, 2000, p. 57-60.

BUZINARO, M. G.; MISTIERI, M. L. A.; CARVALHO, A. A. B.; et al. Prevalência de Rotavírus do grupo A em fezes diarreicas de bezerros de corte em sistema semi-intensivo de produção. Arquivo Brasileiro de Medicina Veterinária e Zootecnia, v. 55, n. 5, p. 266-270, 2003.

CASTRUCCI, G.; FRIGERI, F.; FERRARI, M.; et al. The protection of newborn calves against experimental rotavírus infection by feeding mammary secretions from vaccinated cows. Microbiologica, v. 11, n. 4, p. 379-385, 1988.

CHUCRI, T. M.; MONTEIRO, J. M.; LIMA, A. R.; et al. A review of immune transfer by the placenta. Journal of Reproductive Immunology, v. 87, n. 1-2, p. 14-20, 2010.

COURA, F. M.; LAGE, A. P.; HEINEMANN, M. B. Patotipos de Escherichia coli causadores de diarreia em bezerros: uma atualização. Pesquisa Veterinária Brasileira, v. 34, n. 9, p. 811818, 2014.

DIRKSEN, G.; GRÜNDER, H. D.; STÖBER, M. Rosenberger: Exame Clínico dos Bovinos. 3. ed. Rio de Janeiro: Guanabara Koogan, 1993. 419p.

FILHO, J. P. O.; SILVA, D. P. G.; PACHECO, M. D.; et al. Diarreia em bezerros da raça Nelore criados extensivamente: estudo clínico e etiológico. Pesquisa Veterinária Brasileira, Rio de Janeiro, v. 27, n. 10, p. 419-424, 2007.

GORDON, H. M. C. L.; WHITLOCK, H. V. A new technique for counting nematode eggs in sheep faeces. Journal Council Sceinci Industrial Research Australian, v. 12, n. 1, p. 50-52, 1939.

GULLIKSEN, S. M., LIE, K. I.; SOLVEROD, L.; et al. Risk factors associated with colostrum quality in norwegian dairy cows. Jornal of Dairy Science, v. 91, n. 2, p. 704-712, 2008. 
JAIN, N. C. Essentials of veterinary hematology. Philadelphia: Lea \& Febiger, 1993. 417p.

LESLIE, K. E.; TODD, C. G. Keeping your calves healthy. WCDS Advances in Dairy Technology, n. 19, p 285-300, 2007.

PEREIRA, H. G.; AZEREDO, R. S.; LEITE, J. P.; et al. Electrophoretic study of the genome of human rotaviruses from Rio de Janeiro, São Paulo and Pará, Brazil The Journal of hygiene, $v$. 90, n. 1, p. 117-125, 1983.

QUINN, P. J.; CARTER, M. E.; MARKLEY, B. G.; et. al. Clinical Veterinary Microbiology. London: Wolfe, 1994. 654p.

RAMIG, R. F. Pathogenisis of intestinal and systemic rotavírus infection. Journal of Virology, v. 78, n. 19, p. 10213-10220, 2004.

SAIF, L. J., JIANG, B. Nongroup A rotavíruses of humans and animals. In: RAMIG, R. F. (Ed.). Rotavíruses. Berlin: Springer-Verlag, p. 339-371, 1994.

SANTOS, G. T. Imunidade passiva colostral em bovinos. 2001. NUPEL-UEM. Disponível em: <http://www.nupel.uem.br/passivacolostral.pdf> Acesso em setembro, 2014.

SANTOS, S. A.; RENNÓ, F. P.; ALVES, N. G.; et al. Condição corporal ao parto e produção de leite sobre o desempenho reprodutivo de vacas holandesas em lactação. Revista Brasileira de Saúde e Produção Animal, v. 11, n. 3, p. 919-931, 2010.

THRALL, M. A. Hematologia e bioquímica clínica veterinária. São Paulo: Roca, 2007, 582p.

TIZARD, I. R. Imunologia Veterinária: uma introdução. 6. ed. São Paulo: Roca, 2002. 532p.

VASSEUR, E.; BORDERAS, F.; CUE, R. I.; et al. A survey of dairy calf management practices in Canada that affect animal welfare. Journal of Dairy Science, v. 93, n. 3, p. 1307-1315, 2010.

VEGA, C.; BOK, M.; CHACANA, P.; et al. Egg yolk IgY: Protection against rotavírus induced diarrhea and modulatory effect on the systemic and mucosal antibody responses in newborn calves. Veterinary Immunology and Immunopathology, v. 142, n. 3-4, p. 156-169, 2011.

WALKER, P. G.; CONSTABLE, P. D.; MORIN, D. E.; et al. A reliable, practical, and economical protocol for inducing diarrhea and severe dehydration in the neonatal calf. Canadian Journal of Veterinary Research, v. 62, n. 3, p. 205-213, 1998.

WEI, S.; GONG, Z.; CHE, T.; et al. Genotyping of calves rotavírus in China by reverse transcription polymerase chain reaction. Journal of Virological Methods, v. 189, n. 1, p. 3640, 2013. 
WHITLOCK, R. H. Diarrhea in cattle. In ANDERSON, N. V. Veterinary Gastroenterology. Philadelphia: Lea \& Febiger, cap. 31, p. 755-802, 1992.

Autor para correspondência: Viviane Rohrig Rabassa. ${ }^{1}$ NUPEEC-Núcleo de Pesquisa, Ensino e Extensão em Pecuária, Faculdade de Veterinária/UFPEL, Campus Universitário, Capão do Leão (RS). CEP 96010-900, CP 354. vivianerabassa@gmail.com 